\title{
Etnobotânica de Leguminosae entre agricultores agroecológicos na Floresta Atlântica, Araponga, Minas Gerais, Brasil
}

Ethnobotany of Leguminosae among agroecological farmers in the Atlantic Forest, Araponga, Minas Gerais, Brazil

\author{
José Martins Fernandes ${ }^{1,5}$, Flávia Cristina Pinto Garcia ${ }^{1}$, Maria Christina de Mello Amorozo ${ }^{2}$, \\ Livia Constancio de Siqueira ${ }^{1}$, Carolina Pellucci Barreto Marotta ${ }^{3}$ \& Irene Maria Cardoso ${ }^{4}$
}

\begin{abstract}
Resumo
O trabalho apresenta a riqueza de Leguminosae utilizada por 21 agricultores tradicionais em sistemas agroflorestais (SAFs) cafeeiros e fragmentos florestais na Floresta Atlântica, município de Araponga, Minas Gerais, Brasil, e as categorias de uso, importância relativa e similaridade das espécies entre os SAFs. Os dados foram obtidos através de entrevistas semiestruturadas e observação participante, entre agosto de 2005 e novembro de 2006, durante caminhadas direcionadas em sete SAFs e fragmentos florestais no entorno do Parque Estadual da Serra do Brigadeiro. Os agricultores citaram 59 espécies de Leguminosae; 86\% são nativas da Floresta Atlântica, utilizadas em práticas culturais antigas, como para fazer carro de boi. Foram estabelecidas 12 categorias de uso, das quais as mais importantes foram adubo e lenha ( $21 \mathrm{spp}$ cada). Nos SAFs, as espécies que adubam o solo (18 spp) são as mais utilizadas, e na floresta, para lenha e tecnologia (17 spp). O índice de importância relativa mostrou que na floresta, Piptadenia gonoacantha apresentou $83 \%$ de concordância quanto ao uso da madeira para cercar pastagem, enquanto nos SAFs, Inga edulis obteve 100\% como alimento. Os SAFs estudados apresentam pouca similaridade em espécies (0,42 da escala Sorensen), devido à capacidade de seleção dos agricultores, proporcionando então, espaços para a conservação de espécies úteis de Leguminosae.
\end{abstract}

Palavras-chave: Fabaceae, sistemas agroflorestais, botânica econômica, uso e conservação.

\begin{abstract}
This study describes the richness of Leguminosae used by 21 traditional farmers in coffee agroforestry systems (AFS) and forest fragments of the Atlantic Forest, in the municipality of Araponga, Minas Gerais, Brazil. It also presents the use categories, relative importance and the species similarity between the AFSs. Data were collected through semi-structured interviews and participant observation, between August 2005 and November 2006, directed during random walks in seven AFSs and forest fragments surrounding the State Park of Serra do Brigadeiro. The farmers cited 59 species of Leguminosae, of which $86 \%$ are native to the Atlantic Forest and used in ancient cultural practices, such as to make bullock carts. Twelve categories of use were established, among them the most important were fertilizer and firewood (21 spp each); in the AFSs, species used for soil fertilization (18 spp) are the most utilized, and in the forest, the species for firewood and technology (17 spp.) The relative importance index showed that in the forest, Piptadenia gonoacantha showed $83 \%$ of agreement for the use as wood for fencing pastures, while in the AFSs, Inga edulis scored 100\% as food. The AFSs studied show little similarity of species ( 0.42 of the Sorensen scale), due to the selection promoted by the farmers, thus, providing room for the conservation of useful species of Leguminosae.
\end{abstract}

Key words: Fabaceae, agroforestry systems, economic botany, conservation and use

\footnotetext{
${ }^{1}$ Universidade Federal de Viçosa (UFV), Depto. Biologia Vegetal, Programa de Pós-graduação em Botânica, Av. P.H. Rolfs s/n, 36570-000, Viçosa, MG, Brasil.

${ }^{2}$ Universidade Estadual Paulista Júlio de Mesquita Filho, Inst. Biociências de Rio Claro, Depto. Ecologia, Av. 24-A 1515, Bela Vista, 13506-900, Rio Claro, SP, Brasil.

${ }^{3}$ Universidade Federal de Viçosa (UFV), Centro de Ciências Agrárias, Depto. Engenharia Florestal, Av. P.H. Rolfs s/n, 36570-000, Viçosa, MG, Brasil.

${ }^{4}$ Universidade Federal de Viçosa (UFV), Centro de Ciências Agrárias, Depto. Solos, Av. P.H. Rolfs s/n, 36570-000, Viçosa, MG, Brasil.

${ }^{5}$ Autor para correspondência: fernanbio@bol.com.br
} 


\section{Introdução}

Leguminosae é considerada a terceira maior família entre as angiospermas, com 727 gêneros e cerca de 19.325 espécies, com distribuição cosmopolita (Lewis et al. 2005). No Brasil, ocorrem cerca de 210 gêneros e 2.694 espécies, sendo a família mais diversa no país (Lima et al. 2012). Está presente em todos os domínios fitogeográficos brasileiros, em especial no Cerrado, com 1.158 espécies, Floresta Amazônica, com 1.103 espécies, e Floresta Atlântica, com 939 espécies (Lima et al. 2012).

No Brasil, em alguns estudos as Leguminosae úteis também se destacam em relação às outras famílias botânicas (Balée 1987; Albuquerque \& Andrade 2002; Silva \& Andrade 2005; Pasa et al. 2005; Bortolotto 2006; Botrel et al. 2006). Em trabalhos realizados em outros países, como Bolívia (Dewalt et al. 1999; Vidaurre et al. 2006), Etiópia (Gemedo-Dalle et al. 2005), México (Toledo et al. 1995; Tacher et al. 2002) e Tanzânia (Luoga et al. 2000), Leguminosae se destaca também em relação às outras famílias em número de espécies úteis.

Com a ameaça das florestas, em especial da Floresta Atlântica, tem levado a sociedade brasileira a encontrar alternativas que conciliem o uso sustentável dos bens e serviços das florestas, como o uso da agroecologia (Coelho et al. 2005). A agroecologia estuda os agroecossistemas (Altieri 1989), sendo uma ciência em construção com características transdisciplinares integrando conhecimentos de diversas ciências, inclusive o conhecimento tradicional (Feiden 2005).

Os sistemas agroflorestais (SAFs) mantêm cultivos agrícolas consorciados com espécies vegetais de diferentes hábitos em uma mesma área, com ou sem a presença de animais (Adams 2000), e como existe uma grande preocupação mundial com a perda da diversidade biológica nas regiões tropicais (Tacher et al.2002), os SAFs tornam-se fundamentais para a conservação de espécies da flora e da fauna.

Leguminosae tem sido bastante utilizada em SAFs pela diversidade de espécies, capacidade de associar-se a bactérias fixadoras de nitrogênio no solo e a fungos micorrízicos, produção de matéria orgânica, cobertura do solo, sombreamento das culturas e como fonte de recursos madeireiros e alimentares para agricultores, animais domésticos e silvestres (Cardoso et al. 2003; Lewis et al. 2005; Fernandes 2007). Os sistemas agroflorestais diversos têm sido incentivados em especial entre os agricultores agroecológicos por conciliar conservação ambiental e produção.

O objetivo da pesquisa foi identificar as espécies úteis de Leguminosae entre agricultores agroecológicos no município de Araponga, Minas Gerais, Brasil; conhecer as categorias de uso das espécies em fragmentos florestais e SAFs; analisar a importância relativa das espécies, tornando-se possível verificar a concordância de uso entre os agricultores; e verificar a similaridade das espécies úteis entre os SAFs.

\section{Material e Métodos}

$\mathrm{O}$ estudo foi desenvolvido no município de Araponga, Zona da Mata, Sudeste de Minas Gerais, no entorno do Parque Estadual da Serra do Brigadeiro (PESB), Brasil (Fig. 1). A vegetação é caracterizada como floresta estacional semidecidual, floresta ombrófila densa e aberta e campos de altitude, sob domínio da FA(Veloso et al. 1991). O clima é do tipo $\mathrm{CW}_{\mathrm{b}}$ a $\mathrm{CW}_{\mathrm{a}}$ (mesotérmico), a precipitação anual varia de 1.200 a $1.800 \mathrm{~mm}$, o relevo é montanhoso com declividade entre 20 a $45 \%$ nas encostas, com altitude média de 1.000 metros, e o solo predominantemente é o Latossolo (Golfari 1975).

$\mathrm{O}$ município foi fundado em 1.781 para a exploração do ouro, mas com a decadência em meados

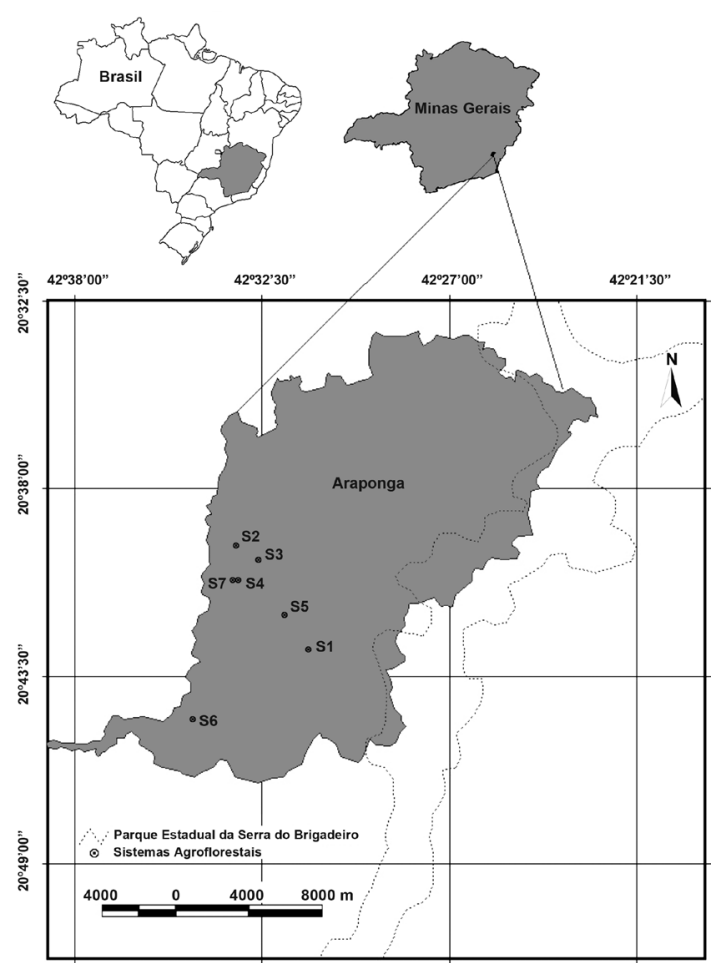

Figura 1 - Localização dos sistemas agroflorestais (SAFs) onde foi realizado o estudo etnobotânico, Minas Gerais, Brasil.

Figure 1 - Location of the agroforestry systems (AFSs) where the ethnobotanical study was conducted, Minas Gerais, Brazil. 
do século XIX, a cafeicultura foi introduzida na região, inicialmente, com a formação de grandes fazendas trabalhadas por mão de obra escrava (Leles 1986; Alves 2006). De acordo com o IBGE (2010), o município tem cerca de 8.152 habitantes, dos quais, em torno de $63 \%$ vivem no meio rural. As principais atividades econômicas na região estão baseadas na cafeicultura, pecuária e no cultivo de feijão, milho, cana-de-açúcar e mandioca, entre outras culturas alimentares.

O estudo etnobotânico aqui apresentado foi realizado com agricultores/as agroecológicos do município de Araponga (Minas Gerais, Brasil), que, em 1994, implantaram SAFs, em um processo de experimentação participativa desenvolvida pelo Centro de Tecnologias Alternativas da Zona da Mata (CTA/ ZM) em parceria com o Sindicato de Agricultores do município de Araponga e Universidade Federal de Viçosa (UFV). Neste município, os SAFs vêm contribuindo para a conservação de espécies locais, estabilização da produção e geração de outras fontes de renda para o agricultor familiar, utilizando-se, como base, conhecimento e experiências das populações locais para uma nova forma de agricultura, com práticas alternativas, ecológicas e sustentáveis (Cardoso et al. 2001).

A sistematização da experimentação participativa, realizada em 2006 (Souza et al. 2010), apontou a necessidade de estudos para identificar a diversidade de espécies vegetais nos SAFs. Esta necessidade levou à elaboração de um projeto sobre a diversidade florística e etnobotânica em SAFs e florestas do entorno do Parque Estadual da Serra do Brigadeiro, do qual o estudo aqui apresentado faz parte (Fernandes 2007; Siqueira 2008).

$\mathrm{O}$ estudo etnobotânico ocorreu em sete sistemas agroflorestais e em fragmentos florestais próximos às residências dos agricultores. Estes fragmentos, segundo Fernandes \& Garcia (2008), em sua grande maioria, são compostos por floresta secundária proveniente de regeneração.

O SAFs apresentavam, na época do estudo, entre 10 e 14 anos de implantação, com área entre 0,5 a 1,5 ha, totalizando no geral 5,5 ha. Têm como cultura principal o café (Coffea arabica L.), consorciado com espécies do estrato arbóreo, arbustivo e herbáceo. As propriedades com SAFs, escolhidas para a pesquisa, estão localizadas aproximadamente a quatro quilômetros do PESB. Seis dos SAFs foram escolhidos por estarem entre os melhores exemplos em termos de produtividade e biodiversidade, de acordo com a avaliação dos agricultores técnicos (Souza et al. 2010) e o sétimo foi escolhido por estar localizado na proximidade dos fragmentos e dos demais SAFs.

Para a obtenção dos dados etnobotânicos, foram entrevistados 21 agricultores residentes no município de Araponga, entre agosto de 2005 e novembro de 2006. Foram entrevistados sobre os SAFs 12 agricultores e sobre áreas de floresta nativa 14 agricultores. Nos SAFs, os agricultores foram escolhidos por serem responsáveis pelo seu manejo, enquanto, para a pesquisa nos fragmentos florestais, foram escolhidos pelo método "bola de neve" (Albuquerque \& Lucena 2004a). Um informante "chave", neste caso o morador mais antigo na comunidade, foi escolhido, passando a indicar outros especialistas do município de Araponga. Posteriormente, foram selecionados 12 agricultores, considerados com maior conhecimento sobre os recursos vegetais e seus usos.

Foram obtidas informações socioeconômicas de todos os envolvidos na pesquisa, como nome do agricultor, comunidade residente, naturalidade, idade, escolaridade, ocupação profissional, tempo de moradia na propriedade, rota de migração e ascendência.

Nos SAFs, as entrevistas foram realizadas durante caminhadas direcionadas, em que os agricultores eram perguntados sobre o tamanho, tempo de implantação e condições do solo antes e depois da implantação do SAF; critério de escolha, manejo e respostas das plantas; qualidade de vida da família após a implantação do SAF; e rendimento financeiro. Quanto às espécies utilizadas no SAF, perguntou-se sobre seus nomes populares, tipos de usos, partes utilizadas, origens do conhecimento e fontes do recurso para implantação nos SAFs. A observação participante também foi realizada durante o estudo (Albuquerque \& Lucena 2004a).

Nas florestas, utilizou-se de entrevistas semiestruturadas e abertas durante caminhadas em trilhas preexistentes, sob a forma de turnê guiada (Albuquerque \& Lucena 2004b). A pergunta chave foi: Quais plantas você conhece e como são utilizadas? As informações foram anotadas e gravadas com autorização dos agricultores. Após a coleta de dados das plantas úteis entre os agricultores, às informações sobre as Leguminosae foram separadas das outras famílias botânicas e apresentadas no presente trabalho.

Os participantes da pesquisa assinaram um termo de consentimento livre e esclarecido, afirmando que foram convidados a participar da pesquisa e que concordaram em disponibilizar as informações etnobotânicas e imagens pessoais para fins científicos. 
Amostras férteis e/ou estéreis dos espécimes vegetais foram coletadas durante as entrevistas, prensadas e desidratadas, seguindo as técnicas usuais (Bridson \& Forman 1999), tendo sido identificadas no Laboratório de Taxonomia Vegetal da UFV com base na literatura especializada. No presente trabalho, Leguminosae foi considerada com as subfamílias Caesalpinioideae, Mimosoideae e Papilionoideae (Lewis et al. 2005). As amostras botânicas foram registradas e depositadas no acervo do Herbário VIC da UFV.

Todas as categorias de uso foram estabelecidas após a coleta de dados. Os dados foram analisados de forma qualitativa no uso de relatos e quantitativa, aplicando-se o índice adaptado por Amorozo \& Gély (1988). Este índice avaliou a importância relativa das espécies entre os agricultores, bem como sua concordância de uso para as plantas com quatro ou mais citações, tornando-se significativo acima de $80 \%$ (CUPc). As espécies citadas pelos agricultores nos SAFs também foram submetidas à análise de agrupamento, utilizando-se a escala de Sorensen, com ligação da média de grupo (UPGMA), realizado pelo programa MVSP $3.13 \mathrm{~m}$ (Kovach Computing Services 2006).

\section{Resultados e Discussão}

Informações socioeconômicas

Todos os agricultores que participaram da pesquisa nasceram no Estado de Minas Gerais, no entorno do PESB. Predominou a participação do sexo masculino, com 16 agricultores, por serem os principais conhecedores dos recursos da floresta. Quanto à faixa etária, 12 estão entre 21 e 42 anos, e nove entre 49 e 75 anos. Entre os agricultores, 14 sempre moraram no meio rural, enquanto o restante já residiu no meio urbano. São agricultores que apresentam miscigenação entre negros, europeus e índios da etnia Puri (Leles 1986; Alves 2006), não mais reconhecida pela Fundação Nacional do Índio, mas reconhecida por moradores locais.

Todos residem em casas de alvenaria com madeiramento da própria região, construídas nos vales e ocupadas há várias gerações pela mesma família. Dão muita importância às nascentes que abastecem as casas com água potável, pela força da gravidade, protegendo-as contra o pisoteio dos animais domésticos.

Algumas práticas culturais são marcantes, como o uso do fogão a lenha e do carro de boi. A presença do fogão a lenha é comum a todas as casas, construído na parte interna e abastecido com lenha obtida nos SAFs e fragmentos florestais próximos. É indispensável no preparo dos alimentos com a tradicional "panela de ferro" e para aquecer a família no período do frio. Quanto ao carro de boi, ainda é utilizado por várias famílias envolvidas no estudo, como meio de transporte da produção agrícola e lenha. Este meio de transporte, comum na região, é uma expressão cultural que exige amplo conhecimento tecnológico e de madeiras diferenciadas para sua construção.

Os sistemas de produção dos agricultores têm por base a cafeicultura, pecuária, apicultura e no cultivo de feijão, milho, arroz, cana-deaçúcar, mandioca e de diversas espécies frutíferas e hortaliças, e estão próximos às casas. É comum entre os agricultores fazer o preparo e o manejo dos SAFs em conjunto, em especial a colheita do café, facilitando a troca de conhecimento etnobotânico. A produção agrícola e seus derivados são para consumo da família, de animais domésticos e para comercialização dos excedentes, como acontece no mercado de propriedade dos agricultores agroecológicos.

Os agricultores participantes deste estudo adotam como prática a implantação de SAFs em suas propriedades. Agricultores da região que não adotam essa prática de cultivo não apresentam o conhecimento sobre as espécies utilizadas para adubar os SAFs, apesar de saberem sobre esse tipo de agricultura praticada no entorno do PESB. Os que têm SAFs relataram a importância do cultivo diferenciado do café consorciado com outras espécies vegetais. Segundo os agricultores, este tipo de cultivo potencializa o melhor funcionamento da lavoura quanto à adubação e cobertura do solo, uso do espaço como fonte de lenha, madeira para construção e como alimento para a família, animais domésticos e silvestres. Segundo Cardoso et al. (2001), os principais objetivos dos agricultores ao implantar os SAFs em suas propriedades foram revitalizar as propriedades do solo, aumentando a ciclagem de nutrientes e reduzindo a erosão, aumentar a produção e melhorar a qualidade do café e diversificar a produção agrícola, principalmente para subsistência familiar, bem como buscar melhorias na qualidade de vida.

Esses agricultores agroflorestais consideram importante o cultivo do café com espécies de diferentes estratos. Segundo o relato de um dos agricultores: "é possível produzir, consorciar, com um retorno razoável e, às vezes, para quem tem uma pequena propriedade, você produz o café, produz o feijão, produz um moirão de cerca, produz uma 
madeira para fazer tábua, tudo no mesmo espaço. Na monocultura, tem que plantar cada um num espaço separado. É mais difícil para quem tem pequena propriedade" (Sr. I.J. de M.L., 33 anos, Araponga, 2006).

Neste relato, o agricultor destacou o retorno que o SAF pode trazer para a família pela produção diversificada em pequena propriedade. Segundo o agricultor, o café e outros alimentos são produzidos na mesma área, além disto, ainda se produz madeira para o uso na própria propriedade, enquanto nas monoculturas, não são produzidos estes recursos diversificados. O uso múltiplo dos solos é uma prática que vem desde os tempos pré-históricos até os tempos atuais, o que permite o cultivo de diversas espécies no mesmo espaço, favorecendo a seleção de novas variedades de importância agrícola (Amorozo 1998; Peroni 2004).

\section{Leguminosas úteis}

Foram reconhecidas pelos agricultores 59 espécies de leguminosas com algum tipo de uso (Tab. 1). São 39 espécies nos SAFs e 37 na floresta, com 17 espécies em comum aos dois sistemas manejados. Não se sabe da existência de outro trabalho sobre conhecimento etnobotânico de agricultores agroecológicos para Leguminosae.

Nos mesmos SAFs e florestas de Araponga, os agricultores reconheceram 86 espécies arbóreas (Siqueira 2008) e 84 espécies entre herbáceas, trepadeiras e arbustivas de outras famílias botânicas (Marotta 2008), totalizando 228 espécies de fanerógamas com alguma importância de uso (Tab. 2). Leguminosae destacou-se em número de espécies, seguida por Asteraceae, com 28 espécies.

As espécies arbóreas são as que apresentam maior número de espécies úteis entre os agricultores, com $38(65 \%)$ citadas. Na floresta, foram reconhecidas 30 (81\%) espécies, e, nos SAFs, 23 (60\%). Quanto à origem das espécies, 51 são nativas (Tab. 1), mostrando que este bioma tão ameaçado tem uma grande diversidade de espécies ainda utilizadas pelos agricultores.

Entre os trabalhos etnobotânicos realizados com agricultores na Floresta Atlântica, podem ser citados o de Christo et al. (2006), que amostraram 20 espécies de Leguminosae, utilizadas por moradores rurais da Gleba Almeida Velha, Estado do Rio de Janeiro, principalmente como remédio, para construção e alimentação humana; Silva \& Andrade (2005), que amostraram 37 espécies úteis em duas comunidades localizadas na Zona do Litoral, Estado de Pernambuco, destacando-se no preparo de remédios e na construção de casas. Comparando-se os dados dos trabalhos citados com os encontrados em Araponga, fica evidente que os agricultores pesquisados, neste trabalho, detêm conhecimento de um grande número de espécies da Floresta Atlântica e que muitas delas são cultivadas nos SAFs como fonte de recursos madeireiros e não madeireiros (Tabs. 1 e 2) como forma de amenizar a retirada da floresta.

Em SAFs, Santos et al. (2004) estudaram a composição florística e o potencial econômico das espécies em áreas no Estado do Pará, sob domínio da Amazônia. Nestes SAFs, 13 espécies de Leguminosae foram consideradas úteis, principalmente como adubo, combustível e para construção, mas também para artesanato e atrativo de caça. Na Floresta Atlântica, nenhum trabalho com este perfil foi encontrado. Uma das principais diferenças de uso entre os SAFs de Araponga e os estudados por Santos et al. (2004) é que os primeiros oferecem alimentos para o retorno da fauna (22 morfoespécies), que enfrentou ação predatória no passado e agora encontra alimento e proteção nos SAFs. Em Cametá, no Pará, os SAFs visam ao uso sustentável da fauna como fonte proteica para os agricultores. A mudança de comportamento entre agricultores em Araponga pode ser observada no comentário do Sr. G.L.C. (37 anos, Araponga, 2006): “Jacu di primeiro o pessoal matava demais! E também as vezes nem tinha alguma coisa pra eles se alimentá. Você vai numa aguinha que eu tenho ali, você vai vê (...) eles não é arisco como era antes. Também o pessoal pegou um pouco de consciência. Antes o pessoal já via um jacu, já ia de espingarda mata, agora (...) aumentou" o número de animais nas roças.

\section{Categorias de uso}

As informações citadas pelos agricultores foram ordenadas em 12 categorias de uso (Tab. 2): oito foram estabelecidas pelos agricultores (adubo, alimentação humana, cobertura do solo, forrageira, lenha, madeira para cercar pastagem, medicinal e sombra) e quatro, pelo grupo de pesquisadores (construção, interação ecológica, tecnologia e outros). As categorias de uso adubo e lenha foram as que incluíram o maior número de espécies, totalizando 21 espécies em cada categoria.

Adubo - Os agricultores citaram 21 espécies que servem como adubo para o solo, devido à produção de folhas e pela capacidade de fixar 


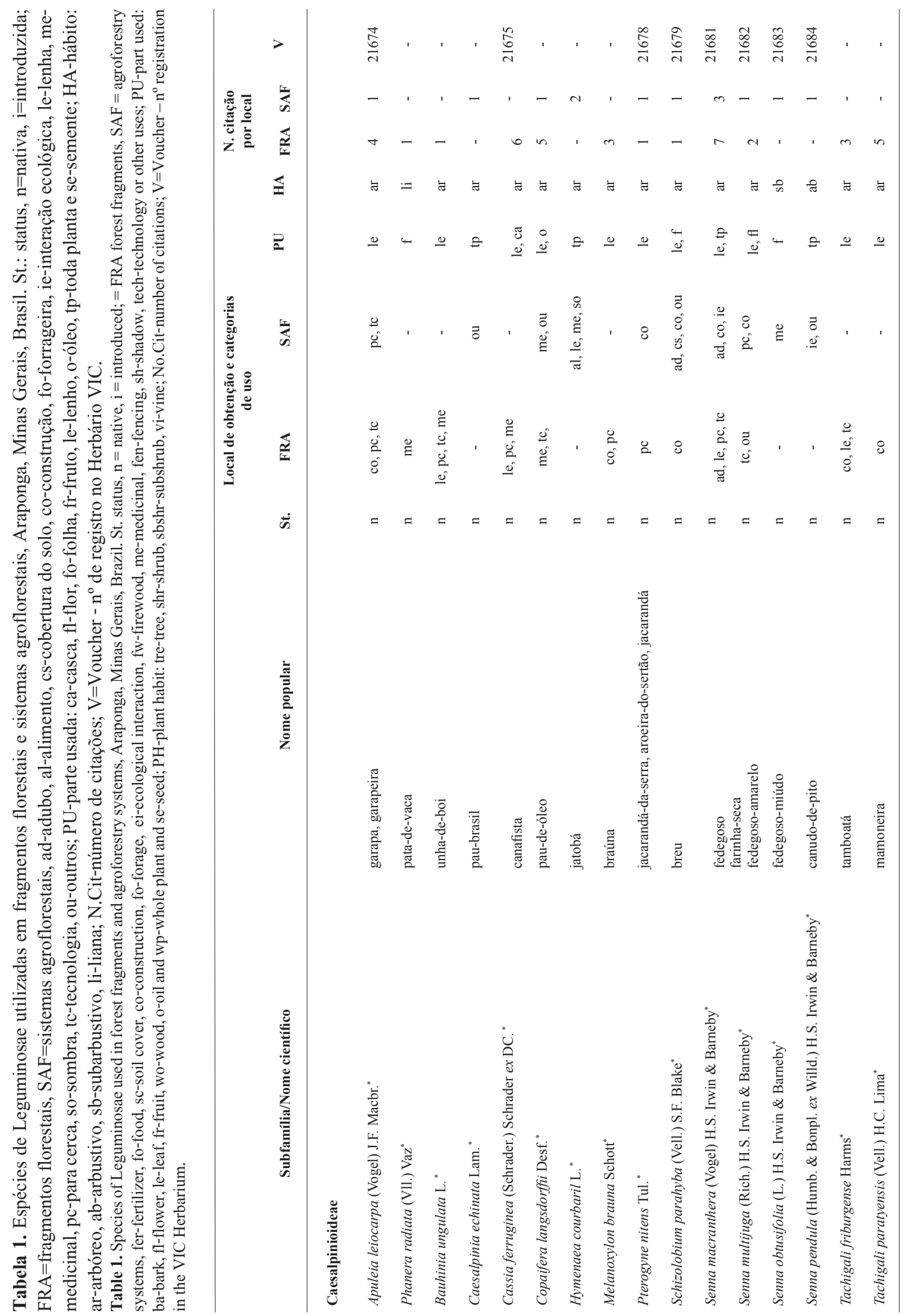




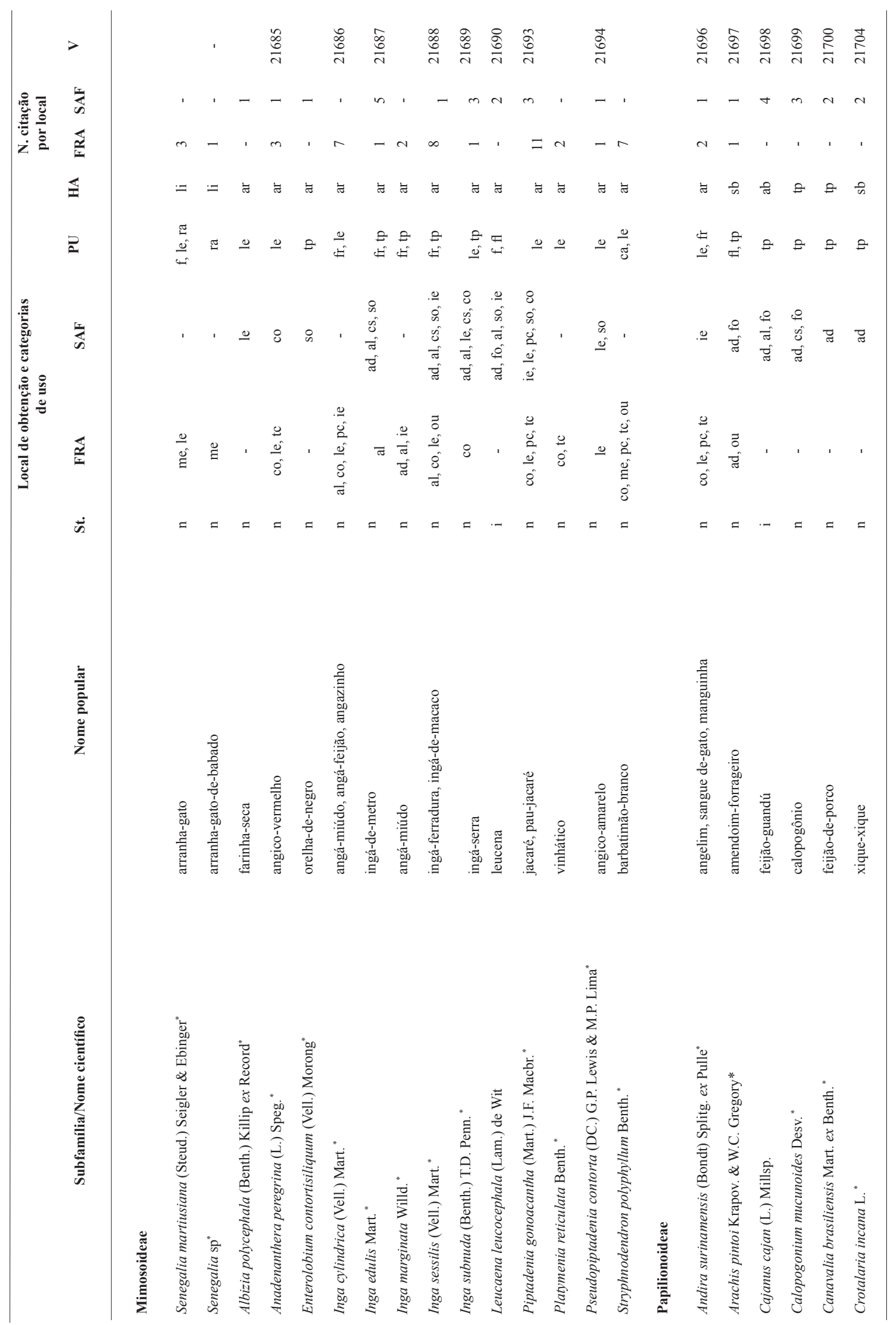




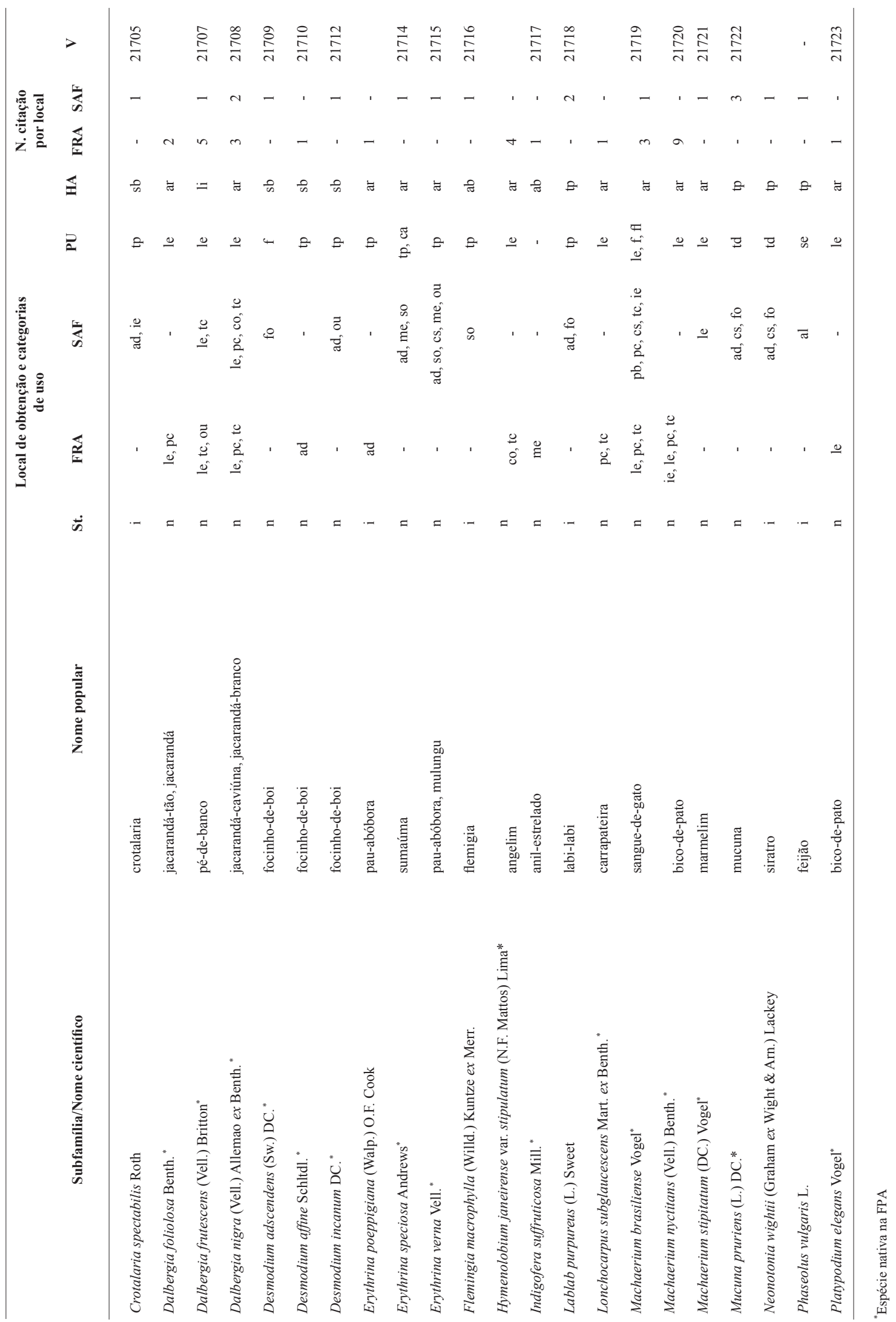


Tabela 2 - Categorias de uso e número de espécies de Leguminosae reconhecidas em fragmentos florestais, sistemas agroflorestais e número total de espécies por categoria em Araponga, MG, Brasil. Fan=fanerógamas úteis em Araponga (Fernandes 2007; Marotta 2008; Siqueira 2008).

Table 2 - Categories of use and number of species of Leguminosae described in the forest fragments, agroforestry systems and total number of species in each category in the municipality of Araponga, MG, Brazil. Fan=fhanerogams useful in Araponga (Fernandes 2007; Marotta 2008; Siqueira 2008).

\begin{tabular}{|c|c|c|c|c|}
\hline \multirow{2}{*}{ Categorias de uso } & \multirow{2}{*}{ Fan. } & \multicolumn{3}{|c|}{ Leguminosae } \\
\hline & & Floresta & SAF & N. total/espécies \\
\hline Adubo & 35 & 5 & 18 & 21 \\
\hline Alimentação humana & 62 & 4 & 6 & 8 \\
\hline Forrageira & 8 & - & 8 & 8 \\
\hline Interação ecológica & 33 & 3 & 8 & 11 \\
\hline Cobertura do solo & 10 & - & 10 & 10 \\
\hline Construção & 67 & 14 & 7 & 16 \\
\hline Lenha & 48 & 17 & 8 & 21 \\
\hline Madeira para cercar pastagem & 16 & 15 & 5 & 16 \\
\hline Medicinal & 105 & 7 & 5 & 11 \\
\hline Sombra & 17 & - & 10 & 10 \\
\hline Tecnologia & 58 & 17 & 4 & 17 \\
\hline Outros & 19 & 4 & 5 & 9 \\
\hline Total & 228 & 37 & 39 & 59 \\
\hline
\end{tabular}

nitrogênio. A grande diversidade de espécies desta categoria está nos SAFs (18 espécies) e ocorre naturalmente em fragmentos florestais. As espécies Inga marginata, Desmodium affine e Erythrina poeppigiana foram citadas como espécies potenciais na adubação, mas ainda não foram testadas e/ou observadas pelos agricultores nos SAFs.

De acordo com a concepção dos agricultores, "leguminosas" são plantas que fixam nitrogênio no solo, principalmente arbóreas, que melhoram e adubam o solo. Segundo Fernandes (2007), das 61 espécies de Leguminosae amostradas nos SAFs de Araponga, 29 apresentam a capacidade de fixação de nitrogênio no solo. Para os agricultores, as informações sobre certas espécies de Leguminosae que adubam o solo foram obtidas em vários encontros organizados pelo CTA/ZM e ou Sindicato Rural dos Agricultores de Araponga e discussões com diferentes profissionais da ciência, como biólogos, agrônomos e engenheiros florestais. Durante estes encontros, os conhecimentos dos agricultores serviram de base para as discussões sobre esta categoria de uso.

Adubo também foi a principal categoria em SAFs de Cametá, PA (Santos et al. 2004). Estes SAFs apresentaram 13 espécies na categoria adubo, mas nenhuma espécie em comum com as 18 encontradas na mesma categoria nos SAFs de Araponga. Espécies adubadeiras são prioridades em SAFs porque reduzem ou eliminam a aplicação de adubos químicos no solo.

Lenha - Nesta categoria, foram incluídas 21 espécies, 17 delas obtidas na floresta e oito nos SAFs. O elevado número de espécies utilizadas nesta categoria é devido ao alto consumo de lenha em atividades diárias das famílias, associado à grande disponibilidade do recurso na floresta e SAFs. As agricultoras são as principais responsáveis pela coleta deste recurso, principalmente de galhos secos encontrados no sub-bosque das florestas, ou resultado das podas dos galhos inferiores das árvores dos SAFs, mas raramente as árvores são cortadas. Os agricultores têm amplo conhecimento das espécies como recurso energético por terem fogão a lenha dentro de suas casas. Além do fogão interno, quase sempre há um fogão construído no quintal, menor e mais simples, usado para cozinhar alimentos para os animais domésticos e para torrar café. Também têm forno de barro no quintal para assar alimentos, como pão e biscoito.

Na floresta, as lenhas das espécies Piptadenia gonoacantha, Senna macranthera e Cassia 
ferruginea foram consideradas, pelos agricultores, de boa qualidade, por produzirem muito volume de madeira, brasa abundante e durável e pouca fumaça. E as espécies Inga cylindrica e Machaerium nyctitans foram consideradas lenha de baixa qualidade, por liberarem muita fumaça na hora da queima e produzirem pouca brasa, devido à baixa densidade da madeira. Segundo Botrel et al. (2006), as espécies M. nyctitans, P. gonoacantha e Platypodium elegans também são utilizadas pelos moradores do município de Ingaí, Minas Gerais, como recurso energético da vegetação nativa. No município de Luminárias, também em Minas Gerais, a população ainda utiliza o fogão a lenha e a serpentina, porque são práticas antigas relacionadas a aspectos culturais (Rodrigues et al. 2002).

Nos SAFs, as espécies mais utilizadas para lenha são nativas da região e de hábito arbóreo (Tab. 1). A retirada da lenha dos SAFs é uma forma de diminuir a pressão de uso dos remanescentes da Floresta Atlântica (Souza et al. 2010).

Tecnologia - Foram incluídas nesta categoria 17 espécies nativas da Floresta Atlântica para fazer algum tipo de artefato ou ferramenta usados em atividades agrícolas e ou pecuárias. Destas 17, apenas quatro espécies são obtidas nos SAFs e também na floresta, portanto, a floresta é a principal fonte de recurso para esta categoria de uso. As espécies que apresentaram maior consenso de uso entre os agricultores foram Dalbergia frutescens (CUPc 45\%), utilizada para fazer arco de peneira, e M. nyctitans (CUPc 36\%), utilizada para fazer canga e carro de boi. Apuleia leiocarpa foi a que apresentou maior variedade de uso (canga, eixo, prancha lateral conhecida como cheda e roda de carro de boi).

Os principais artefatos citados pelos agricultores foram o carro de boi (21 citações), a canga de carro de boi (9 citações) e o arco de peneira (6 citações). Artefatos não fabricados exclusivamente com Leguminosae. O uso do carro de boi é muito comum entre os moradores da região para transportar a produção agrícola e lenha dos SAFs. A peneira é utilizada para abanar os grãos de café, arroz e feijão produzidos na propriedade. Cada peça do carro de boi exige madeira com certas qualidades, e os agricultores selecionam as espécies com base nestas qualidades (Botrel et al. 2006), como, por exemplo, a sucupira (Bowdichia virgilioides Kunth) para as rodas e pereira (Platyciamus regnellii Benth.) para a confecção da cheda.
Para o gado que fica solto no pasto e que tem costume de romper a cerca, os agricultores colocam uma canga no pescoço feita com a madeira de Machaerium brasiliense. Outro utensílio importante na propriedade é o pilão, feito da madeira de Anadenanthera peregrina, usado para socar arroz, por exemplo. A cangalha de burro é instrumento que era muito utilizado no passado para transportar produtos como café e alimentos de Araponga até a cidade de Ouro Preto, mas que foi substituída por caminhão e trator. A principal madeira utilizada na fabricação das cangalhas era proveniente de Stryphnodendron polyphyllum, por ser leve, macia e resistente.

Construção-Foram incluídas nesta categoria 16 espécies, sendo 14 obtidas na floresta e sete nos SAFs (Tab. 1). As espécies são usadas geralmente para fazer tábua, esteio de casa, janela, porta e curral. Construções para os animais são comuns entre os agricultores, devido à pecuária em pequena escala ser bem difundida na região. Nesta categoria, as espécies são obtidas quase que exclusivamente em florestas da região, mas os SAFs são uma fonte alternativa para produção madeireira. Entre as espécies utilizadas em Araponga, Pseudopiptadenia contorta e Dalbergia nigra também são utilizadas entre os moradores rurais da Gleba Aldeia Velha, estado do Rio de Janeiro (Christo et al. 2006).

$\mathrm{Na}$ floresta, Tachigali paratyensis (CUPc 45\%) e Hymenolobium janeirense (CUPc 36\%) estão entre as espécies mais citadas. A primeira espécie merece atenção pela sua conservação na região, porque foi a única citada apenas para fazer tábua. Segundo Fernandes (2007), em estudo taxonômico de Leguminosae em dois fragmentos de Floresta Atlântica, em Araponga, foram observadas apenas duas árvores da espécie, mas ao final das coletas, uma já tinha sido cortada para o uso da madeira. Mesmo assim, os moradores locais se preocupam com a fiscalização do Instituto Estadual de Florestas de Minas Gerais (IEF), mas também querem continuar com suas práticas culturais relacionadas com o uso dos recursos florestais. Para Hanazaki et al. (1996), a proibição do uso dos recursos florestais, por órgão ambientais, poderá desestruturar a organização social dessas populações, bem como a interação com os ecossistemas. Desta forma, políticas públicas são necessárias na região para incentivar o plantio de mudas da espécie nas propriedades rurais.

Madeira para cercar pastagem - Os agricultores citaram 16 espécies que possuem 
madeira de boa qualidade para cercar as pastagens das pequenas propriedades. Nesta categoria, a floresta é o principal local para obtenção de madeira (15 espécies). As espécies de troncos grossos são usadas para fazer os moirões a serem colocados nos cantos do cercado, enquanto aquelas que de troncos finos são usadas para fazer estacas que serão colocadas entre os moirões.

As espécies mais usadas são oriundas da floresta, destacando-se P. gonoacantha (CUPc 81,8\%), C. ferruginea (CUPc 54\%), A. leiocarpa (CUPc 18\%) e S. macranthera, facilmente encontradas na vegetação nativa e usadas para fazer estacas e moirões de cerca, exceto a última, que é usada apenas para estaca. Esta categoria está bem difundida entre os agricultores porque a pecuária é tão antiga quanto a cafeicultura na região. As primeiras fazendas formadas na Zona da Mata de Minas Gerais para a implantação de pastagens e café a pleno sol datam de meados do século XIX, tendo os caboclos como responsáveis pela derrubada feita com as técnicas aprendidas com os índios (Valverde 1967; Leles 1986). As espécies mencionadas anteriormente são encontradas em SAFs (Souza et al. 2010), portanto, com potencial de substituição para as madeiras oriundas da floresta. Muitos agricultores, mas que não participaram do trabalho aqui apresentado, já utilizam os galhos destas espécies, podados das árvores das pastagens e cafezal, para cercar as propriedades e nascentes.

Medicinal - Nesta categoria, são incluídas 11 espécies nativas da Floresta Atlântica, 19\%, utilizadas como remédio para os agricultores e animais. $\mathrm{O}$ número de espécies citadas presentes na floresta (7 espécies ) e SAFs (5 espécies) foi similar. Leite et al. (2008), em estudo no entorno do PESB, relataram o uso medicinal de quatro espécies de Leguminosae (Bauhinia variegata L., Cajanus cajan (L.) Millsp., Inga vulpina Mart. ex Benth. e Zornia gemella Vogel), todas diferentes das apresentadas neste estudo. Os fragmentos florestais e os SAFs são provedores de espécies (16 espécies) utilizadas no tratamento das enfermidades das famílias no município.

As espécies da Floresta que apresentaram maior consenso de uso medicinal entre os agricultores foram S. polyphyllum (CUPc 63\%) e Copaifera langsdorffii (CUPc 27\%). A última espécie também está entre as principais utilizadas como medicinal em áreas de Cerrado e Caatinga (Albuquerque \& Andrade 2002; Pasa et al. 2005).
As espécies Bauhinia radiata, C. ferruginea e Indigofera suffruticosa foram citadas, mas os entrevistados não especificaram para qual finalidade.

Nos SAFs, as espécies medicinais mencionadas são nativas (Tab. 1), como Erythrina speciosa, Erythrina verna e Hymenaea courbaril, e foram obtidas pela coleta de sementes em fragmentos florestais distantes das casas. Esta prática mostra o interesse dos agricultores em aumentar o número de espécies medicinais nas proximidades das casas, as quais não são encontradas facilmente na floresta.

Alimentação da fauna silvestre, alimentação humana e forrageira - Nestas três categorias de uso, foram incluídas 21 espécies, 11 para alimentação da fauna silvestre, oito para alimentação humana e duas para forragem.

Na categoria alimentação da fauna silvestre, os agricultores conhecem várias espécies de Leguminosae que oferecem recursos alimentares para abelha, macaco, morcego e pássaros. Foram citadas sete espécies visitadas pelas abelhas na época da floração, destas, apenas $M$. nyctitans foi citada como presente na floresta. Estas espécies, além de contribuírem para o aumento da produção de mel para os vários agricultores que possuem apiários em suas propriedades, contribuem também para o aumento da produção do café, pois atraem polinizadores na época da sua floração (De Marco \& Coelho 2004). Ferreira (2008) observou nove espécies de polinizadores visitando as flores do cafeeiro em SAFs em Araponga.

Na categoria alimento humano, destacaramse as espécies I. cylindrica, I. marginata, Inga edulis e Inga sessilis, encontradas na floresta, por apresentarem uma massa branca adocicada (sarcotesta) que envolve o embrião. Essa massa é muito apreciada, tanto pelas crianças como pelos adultos, mas as duas primeiras espécies são consumidas pelas crianças devido aos frutos serem menores. Segundo Pennington \& Fernandes (1998), as espécies de ingás são consideradas uma fonte importante na alimentação humana e têm uma história de utilização que se estende há mais de 2.000 anos, quando eram cultivadas pelos habitantes pré-colombianos do Peru. Nos SAFs, as espécies de ingá também são utilizadas, principalmente a I. edulis (CUPc 100\%), que obteve a maior concordância de uso entre os agricultores. Quanto ao uso das espécies de feijão, Phaseolus vulgaris L. é a preferida pelos agricultores, sendo plantada geralmente em áreas fora dos SAFs, onde a 
capina é uma prática comum. C. cajan está presente nos SAFs, mas com o objetivo de adubação verde, já que não é muito consumida pelas famílias.

As espécies forrageiras como Arachis pintoi e de Leucena leucocephala e sementes de Lablab purpureus e Mucuna pruriens são obtidas exclusivamente nos SAFs e delas são utilizadas principalmente as folhas como ração para porcos e galinhas. Entre os moradores tradicionais que vivem em áreas de Caatinga no município de Floresta, estado de Pernambuco, as plantas forrageiras são as que agregam o maior número de espécies úteis para a alimentação dos animais (Ferraz et al. 2006). Para Lewis \& Owen (1989), as espécies de Leguminosae destacam-se como alimento animal devido aos altos índices de proteína, principalmente em folhas, frutos, raízes e flores.

Cobertura do Solo - Esteve representada por nove espécies, predominantemente arbóreas (6 espécies) e exclusivas dos SAFs, com a finalidade de manter a umidade no solo e protegê-lo contra a erosão. Durante as caminhadas na floresta, nenhum entrevistado mencionou qualquer espécie de Leguminosae para este tipo de uso, pois não se usa o solo da floresta para cultivos, mas a floresta serve como fonte de sementes e mudas a serem utilizadas nos SAFs. S. macranthera, I. edulis e Calopogonium mucunoides se destacaram nesta categoria: as duas primeiras pelo fornecimento de folhas para a cobertura do solo e ciclagem de nutrientes e a última pelo seu sistema radicular, que serve para estruturar o solo e evitar erosão. A cobertura do solo é importante para os agricultores agroecológicos de Araponga, em função de os SAFs estarem localizados em áreas com grande declividade, geralmente $45 \%$, acarretando perda de solo pela erosão. As perdas de solo e de nutrientes em SAFs são menores do que em monoculturas, para isto contribui não só o estrato arbóreo mas também estrato herbáceo (Franco et al. 2002).

Sombra - Esta categoria mencionada para os SAFs incluiu dez espécies nativas. Para os agricultores, fazem parte desta categoria as plantas que ajudam a diminuir os efeitos da radiação solar na cultura cafeeira e no solo. Também facilitam o manejo dos SAFs, principalmente em horários de maior radiação. Em Araponga, os agricultores ordenaram as planta como de grande, médio e pequeno porte, influenciando diretamente na formação da sombra. Entre as espécies de grande porte, podem ser citadas I. edulis, H. courbaril,
Enterolobium contortisiliquum, E. speciosa, $P$. contorta e I. sessilis; médio porte, E. speciosa; e de pequeno porte, Flemigia macrophylla. Também foram mencionadas aquelas espécies caducifólias, como E. speciosa e E. verna, que, durante o amadurecimento dos frutos, perdem completamente as folhas, acelerando o processo de colheita dos grãos de café.

\section{Importância relativa das espécies}

Entre as espécies citadas pelos agricultores, 14 apresentaram CUP acima de 40\%, correspondendo a 24\% das espécies úteis (Tab. 3). Todas as espécies são arbóreas e nativas da região, exceto a arbustiva C. cajan.

P. gonoacantha (CUPc 81,8\%) foi a espécie com maior concordância de uso, quando obtida na floresta. Sua madeira é usada para fazer estacas e moirões para as cercas das pastagens. Nos SAFs, a espécie é indesejada pela maioria dos agricultores, devido à produção de muita semente e por apresentar raízes superficiais, competindo com as raízes do café quanto à água. Esta espécie foi a mais encontrada nos SAFs, mas durante o manejo seus indivíduos jovens são cortados (Fernandes 2007). Esta espécie pode chegar a 20 metros de altura e com tronco de até 40 centímetros de diâmetro, e como tem ampla distribuição na Floresta Atlântica, torna-se um recurso fácil de ser encontrado pelos moradores (Tamashiro 1989; Oliveira Filho 2006). Além do emprego da madeira para cercar as pastagens, a espécie também é usada na construção de casas, como lenha e confecção de artefatos, como o carro de boi e prancha de ponte.

Nos SAFs, I. edulis, com $100 \%$ de CUPc, foi a espécie com maior concordância entre os agricultores quanto ao uso alimentar. Seu fruto chega a quase um metro de comprimento. Também foi citada como adubo do solo, devido à produção de folhas, fixação de nitrogênio e cobertura do solo, além de sombrear o cafezal. A espécie ocorre na América do Sul, em toda a região tropical, com exceção das regiões áridas do Nordeste e Planalto Central do Brasil, que se estendem até o Chaco na Argentina (Pennington 1997).

Espécies tradicionalmente conhecidas na região de Araponga pela importância da madeira como Melanoxylon brauna e D. nigra não estiveram entre as mais citadas pela dificuldade dos agricultores encontrá-las nas florestas. Segundo dois informantes mais idosos, estas espécies são madeiras do passado, devido à extração 
Tabela 3 - Usos principais e concordância quanto ao uso das espécies de Leguminosae em fragmentos florestais e SAFs, Araponga(MG). NICUE - $\mathrm{n}^{\circ}$ de agricultores que citou uso da espécie; NICUP $-\mathrm{n}^{\circ}$ de agricultores que citou usos principais; CUP - índice de concordância de uso principal; FC - fator de correção; e CUPc - CUP corrigida. Table 3 - Main uses and agreement regarding the use of Leguminosae species in forest fragments and AFSs, Araponga (MG). NICUE - number of farmers who cited the use of the species; NICUP - No of farmers who cited the major uses; CIPU - concordance index of primary use; $\mathrm{CF}$ - correction factor; and CIPUc - CIPU corrected.

\begin{tabular}{|c|c|c|c|c|c|c|}
\hline Nome Científico & Uso principal & NICUE & NICUP & CUP & FC & CUPc \\
\hline Apuleia leiocarpa & madeira $\mathrm{p} / \mathrm{cerca}$ & 4 & 2 & 50,0 & 0,36 & 18 \\
\hline Cajanus cajan & forrageira & 4 & 3 & 75,0 & 0,80 & 60 \\
\hline Cassia ferruginea & madeira $\mathrm{p} / \mathrm{cerca}$ & 6 & 6 & 100 & 0,54 & 54 \\
\hline Copaifera langsdorffii & medicinal & 5 & 3 & 60,0 & 0,45 & 27 \\
\hline Dalbergia frutescens & tecnologia & 5 & 5 & 100 & 0,45 & 45 \\
\hline Hymenolobium janeirense & construção & 4 & 4 & 100 & 0,36 & 36 \\
\hline Inga cylindrica & alimento & 7 & 4 & 57,1 & 0,63 & 36 \\
\hline Inga edulis & alimento & 5 & 5 & 100 & 1,00 & 100 \\
\hline Inga sessilis & alimento & 8 & 5 & 62,5 & 0,72 & 45 \\
\hline Machaerium nyctitans & tecnologia & 9 & 4 & 44,4 & 0,81 & 36 \\
\hline Piptadenia gonoacantha & madeira $\mathrm{p} / \mathrm{cerca}$ & 11 & 9 & 81,8 & 1,00 & 81,8 \\
\hline Senna macranthera & lenha & 7 & 5 & 71,4 & 0,63 & 45 \\
\hline Stryphnodendron polyphyllum & medicinal & 7 & 7 & 100 & 0,63 & 63 \\
\hline Tachigali paratyensis & construção & 5 & 5 & 100 & 0,45 & 45 \\
\hline
\end{tabular}

desordenada e que estão sendo substituídas pelas mais encontradas atualmente. Segundo Albuquerque \& Andrade (2002), os estudos etnobotânicos indicam que a estrutura de comunidades vegetais e paisagens são sempre alteradas pelas pessoas, tanto sob aspectos negativos, como beneficiando e promovendo os recursos manejados. D. nigra, que está ameaçada de extinção, foi encontrada em dois SAFs de Araponga (Fernandes 2007; Souza et al. 2010).

\section{Similaridade entre os SAFs}

Verificou-se que a similaridade florística entre as espécies de Leguminosae utilizadas nos SAFs foi baixa. Os mais similares foram SAF-5 e SAF-4 com nível de 0,42 da escala Sorensen, apresentando em comum às espécies $C$. cajan, $I$. subnuda, $P$. gonoacantha e $S$. macranthera. Entre o SAFs-3 e SAFs-2 apresentaram em comum as espécies C. cajan, C. mucunoides, H. courbaril, I. edulis e M. pruriens, com nível de 0,35 , confirmando a grande heterogeneidade entre as espécies usadas pelos agricultores.

A baixa similaridade das espécies utilizadas entre os SAFs reforça que esses agricultores, durante a experimentação participativa dos SAFs, tiveram autonomia para selecionar as espécies de acordo com a sua necessidade de uso, conhecimento e disponibilidade de área para plantio (Souza et al. 2010). A baixa similaridade faz com que espécies diferentes apresentem o mesmo tipo de uso. Dados contrários foram encontrados entre SAFs na Amazônia, onde o índice de similaridade para Leguminosae chegou a 0,72 da escala Sorensen (Santos et al. 2004). Este alto índice de similaridade de espécies úteis na Amazônia está provavelmente relacionado à forma de implantação dos SAFs, que é em áreas com uma floresta existente e depois manejada. Em Araponga, os SAFs foram estruturados em áreas degradadas, principalmente com espécies plantadas e/ou espontâneas, que foram selecionadas pelos agricultores.

\section{Conclusões}

Os agricultores agroecológicos que participaram do estudo possuem elevado conhecimento sobre as espécies de Leguminosae, favorecendo a continuidade de tradições locais. As espécies úteis são predominantemente arbóreas e nativas da Floresta Atlântica.

As espécies presentes na floresta são utilizadas especialmente como madeira para 
lenha, artefatos, construção de residências dos agricultores e instalações para os animais. O elevado número de espécie presentes nos SAFs atendem, prioritariamente, as necessidades de adubar, proteger e sombrear o solo e complementar a fonte de recursos madeireiros.

As espécies com maior concordância de uso estão na floresta. São espécies que merecem atenção quanto à conservação na região, para que seus recursos não sejam explorados de forma desordenada, como no passado.

Os SAFs mostraram-se com baixa similaridade, indicando que a autonomia no momento de implantação permitiu que os agricultores escolhessem as espécies de acordo com seus conhecimentos e necessidades, levando a uma alta riqueza das espécies úteis de Leguminosae. São áreas que atuam como corredores ecológicos, favorecendo a flora e a fauna regionais.

\section{Agradecimentos}

Ao CNPq, pela concessão de bolsas de estudo ao primeiro e quarto autores; ao CTA/ZM, FAPEMIG e ao Programa de Pós-Graduação em Botânica da UFV, pelo apoio técnico e financeiro; aos agricultores e Sindicato Rural de Araponga, pela participação nas etapas da pesquisa; e, aos colegas de campo Davi, Edivânia, Helton, Maria Alice, Osvaldo, Rafael e Renatinho.

\section{Referências}

Adams. C. 2000. As roças e o manejo da Mata Atlântica pelos caiçaras: uma revisão. Interciencia 25: 143-150.

Albuquerque, U.P. \& Andrade, L.H.C. 2002. Conhecimento botânico tradicional e conservação em uma área de Caatinga no estado de Pernambuco, nordeste do Brasil. Acta Botanica Brasilica 16: 273-285.

Albuquerque, U.P. \& Lucena, R.F.P. 2004a. Seleção e escolha dos informantes. In: Albuquerque, U.P. \& Lucena, R.F.P. (eds.). Métodos e técnicas na pesquisa etnobotânica. Livro Rápido/NUPEEA, Recife. 189p.

Albuquerque, U.P. de \& Lucena, R.F.P. 2004b. Métodos e técnicas para coleta de dados. In: Albuquerque, U.P. \& Lucena, R.F.P. (orgs.). Métodos e técnicas na pesquisa etnobotânica. Livro Rápido/NUPEEA, Recife. 189p.

Altieri, M.A. 1989. Agroecologia: as bases científicas da agricultura alternativa. $2^{\text {a }}$ ed. PTA-FASE, Rio de Janeiro. 240p.

Alves, M.A. 2006. A “conquista da terra": (re)produção social e (re)construção histórica entre agricultores familiares do município de Araponga, MG. Mana 12: 269-283.

Amorozo, M.C.M \& Gély, A. 1988. Uso de plantas medicinais por caboclos do Baixo Amazonas. Barcarena, PA, Brasil. Boletim do Museu Emílio Goeldi, Série Botânica (supl.) 4: 47-129.

Amorozo, M.C.M. 1998. Um sistema de agricultura camponesa em Santo Antonio do Leverger, MT. In: Fonseca, V.S.; Silva, I.M. \& Sá, C.F.C. (eds.). Etnobotânica: base para a conservação. EDUR, Seropédica. Pp. 121-131.

Balée, W. 1987. A etnobotânica quantitativa dos índios Tembé (Rio Gurupi, Pará). Boletim do Museu Emílio Goeldi, Série Botânica 3: 29-50.

Bortolotto, I.M. 2006. Etnobotânica nas comunidades do Castelo e Amolar, borda oeste do Pantanal brasileiro. Tese de Doutorado.Universidade Estadual Paulista. $158 \mathrm{p}$.

Botrel, R.T.; Rodrigues, L.A.; Gomes, L.J.; Carvalho, D.A. \& Fontes, M.A.L. 2006. Uso da vegetação nativa pela população local no município de Ingaí, MG, Brasil. Acta Botanica Brasilica 20: 143-156.

Bridson, D. \& Forman, L. 1999. The herbarium: handbook. $3^{\text {rd }}$ ed. Royal Botanic Gardens, Kew. 346p.

Cardoso, I.M.; Boddington, C.; Janssen, B.H.; Oenema, O. \& Kuyper, T.W. 2003. Distribuição of mycorrizal fungal spores in soils under agroforestry and monocultural coffee systems in Brazil. Agroforestry Systems 58: 33-43.

Cardoso, I.M.; Guijt, I.; Franco, F.S.; Carvalho, P.S. \& Ferreira-Neto, O.S. 2001. Continual learning for agroforestry system design: university, NGO and farmer partnership in Minas Gerais, Brazil. Agroforestry Systems 58: 33-43.

Christo, A.G.; Guedes-Bruni, R.R. \& Fonseca-Kruel, V.S. 2006. Uso de recursos vegetais em comunidades rurais limítrofes à Reserva Biológica de Poço das Antas, Silva Jardim, Rio de Janeiro: estudo de caso na Gleba Aldeia Velha. Rodriguésia 57: 519-542.

Coelho, D.J.S.; Souza, A.L. \& Oliveira, C.M.L. 2005. Levantamento da cobertura florestal natural da microrregião de Viçosa, MG, utilizando-se imagens de Landsat 5. Revista Árvore 29:17-24.

De Marco, J. \& Coelho, F.M. 2004. Services performed by the ecosystem: forest remnants influence agricultural cultures' pollination and production. Biodiversity and Conservation 13: 1245-1255.

Dewalt, S.J.; Bourdy, G.; Michel, L.R.C. \& Quenevo, C. 1999. Ethnobotany of the Tacana: Quantitative inventories of two permanent plots of northern Bolivia. Economic Botany 53: 237-260.

Feiden, A. 2005. Agroecologia: introdução e conceitos. In: Aquino, A.M.; Assis, R.L. (orgs.). Agroecologia: princípios e técnicas para uma agricultura orgânica sustentável. Embrapa, Brasília. Pp. 49-69. 
Fernandes, J.M. \& Garcia, F.C.P. 2008. Leguminosae em dois fragmentos de floresta estacional semidecidual em Araponga, Minas Gerais, Brasil: arbustos, subarbustos e trepadeiras. Rodriguésia 59: 525-546.

Fernandes, J.M. 2007. Taxonomia e etnobotânica de Leguminosae Adans. em fragmentos florestais e sistemas agroflorestais na Zona da Mata Mineira. Dissertação de Mestrado.Universidade Federal de Viçosa. 223p.

Ferraz, J.S.F.; Albuquerque, U.P. \& Meunier, I.M.J. 2006. Valor de uso e estrutura da vegetação lenhosa às margens do riacho do Navio, Floresta, PE, Brasil. Acta Botanica Brasilica 20: 125-134.

Ferreira, F.M.C. 2008. A polinização como um serviço do ecossistema: uma estratégia econômica para a conservação. Tese de Doutorado. Universidade Federal de Minas Gerais, Viçosa. 89p.

Franco, F.S.; Couto, L.; Carvalho, A.F.; Jucksch, I.; Filho, E.I.F., Silva, E. \& Meira-Neto, J.A.A. 2002. Quantificação de erosão em sistemas agroflorestais e convencionais na Zona da Mata de Minas Gerais. Revista Árvore 26: 751-760.

Gemedo-Dalle, T.; Maass, B.L. \& Isselstein, J. 2005. Plant biodiversity and ethnobotany of Borana Pastoralists in Southern Oromia, Ethiopia. Economic Botany 59: 43-65.

Golfari, L. 1975. Zoneamento ecológico do estado de Minas Gerais para reflorestamento. Série técnica, 3. CPFRC, Belo Horizonte, BR. 65p.

Hanazaki, N.; Leitão-Filho, H.F. \& Begossi, A. 1996. Uso de recursos na Mata Atlântica: o caso da Ponta do Almada (Ubatuba, Brasil). Interciencia 21: 268-276.

IBGE. 2010. Araponga, Minas Gerais. Disponível em $<$ http://www.ibge.gov.br/cidadesat/topwindow. htm?1>. Acesso em Jan 2009.

Kovach Computing Services. 2006. MVSP 3.13m for Windows (computer program manual). Kovach Computing Services, Wales.

Leite, J.P.V.; Fernandes, J.M.; Favaro, L.B.; Gontijo, D.C.; Marotta, C.P.B.; Siqueira, L.C.; Maia, R.T. \& Garcia, F.C.P. 2008. Plantas medicinais no entorno do Parque Estadual da Serra do Brigadeiro. MG Biota 1: 16-34.

Leles, D.C. 1986. História de Araponga. Imprensa Oficial, Belo Horizonte. 117p.

Lewis, G.P. \& Ower, P.E. 1989. Legumes of the Ilha de Maracá. Royal Botanic Gardens, Kew. 95p.

Lewis, G.P.; Schrire, B.D.; Mackinder, B.A. \& Lock, J.M. 2005. Leguminosae of the world. Royal Botanic Gardens, Kew. 577p.

Lima, H.C.; Queiroz, L.P.; Morim, M.P.; Souza, V.C.; Dutra, V.F.; Bortoluzzi, R.L.C.; Iganci, J.R.V.; Fortunato, R.H.; Vaz, A.M.S.F.; Souza, E.R.; Filardi, F.L.R.; Valls, J.F.M.; Garcia, F.C.P.; Fernandes, J.M.; Martins-da-Silva, R.C.V.; Perez, A.P.F.; Mansano, V.F.; Miotto, S.T.S.; Tozzi, A.M.G.A.;
Meireles, J.E.; Lima, L.C.P.; Oliveira, M.L.A.A.; Flores, A.S.; Torke, B.M.; Pinto, R.B.; Lewis, G.P.; Barros, M.J.F.; Ribeiro, R.D.; Schütz, R.; Pennington, T.; Klitgaard, B.B.; Rando, J.G.; Scalon, V.R.; Cardoso, D.B.O.S.; Costa, L.C.; Silva, M.J.; Moura, T.M.; Barros, L.A.V.; Silva, M.C.R.; Queiroz, R.T., Sartori, A.L.B. \& Camargo, R. 2010. Fabaceae. In Lista de espécies da flora do Brasil. Jardim Botânico do Rio de Janeiro. Disponível em $<$ http://floradobrasil.jbrj.gov.br/2012/FB000115>. Acesso em Out 2010.

Luoga, E.J.; Witkowski, T.F. \& Balkwil, K. 2000. Differential utilization and ethnobotany of trees in Kitulanghalo forest reserve and surrounding communal lands, eastern Tanzania. Economic Botany 54: 328-343.

Marotta, C.P.B. 2008. Levantamento etnobotânico das espécies herbáceas e arbustivas em fragmentos florestais no entorno do Parque Estadual da Serra do Brigadeiro, Zona da Mata, Minas Gerais. Relatório de iniciação científica, Universidade Federal de Viçosa. 31p.

Oliveira- Filho, A.T. 2006. Catálogo das árvores nativas de Minas Gerais: mapeamento e inventário da flora nativa e dos reflorestamentos de Minas Gerais. Ed. UFLA, Lavras. 423p.

Pasa, M.C.; Soares, J.J. \& Guarim-Neto, G. 2005. Estudo etnobotânico na comunidade de Conceição-Açu (alto da bacia do rio Aricá Açu, MT, Brasil). Acta Botanica Brasilica 19: 195-207.

Pennington, T.D. \& Fernandes, E.C.M. 1998. The genus Inga utilization. The Royal Botanic Gardens, Kew. $167 \mathrm{p}$.

Pennington, T.D. 1997. The genus Inga: botany. Royal Botanic Gardens, Kew. 844p.

Peroni, N. 2004. Agricultura de pescadores. In: Begossi, A. (org.). Ecologia Humana de pescadores da Mata Atlântica e da Amazônia. HUCITEC, São Paulo. Pp. 59-87.

Rodrigues, L.A.; Carvalho, D.A.; Gomes, L.J. \& Botrel, R.T. 2002. Espécies vegetais nativas usadas pela população local em Luminárias, MG. Boletim Agropecuário da Universidade Federal de Lavras 52: 1-34.

Santos, S.E.M.; Miranda, I.S. \& Tourinho, M.M. 2004. Análise florística e estrutural de sistemas agroflorestais das várzeas do rio Juba, Cametá, Pará. Acta Amazonica 34: 251-263.

Silva, A.J.R. \& Andrade, L.H.C. 2005. Etnobotânica nordestina: estudo comparativo da relação entre comunidades e vegetação na Zona do Litoral - Mata do estado de Pernambuco, Brasil. Acta Botanica Brasilica 19: 45-60.

Siqueira, L.C. 2008. Levantamento florístico e etnobotânico do estrato arbóreo em sistemas naturais e agroflorestais, Araponga, Minas Gerais. 
Dissertação de Mestrado. Universidade Federal de Viçosa, Viçosa. 118p.

Souza, H.N.; Cardoso, I.M.; Fernandes, J.M.; Garcia, F.C.P.; Bonfim, V.R.; Santos, A.C.; Carvalho, A.F. \& Mendonça, E.S. 2010. Selection of native trees for intercropping with coffee in the Atlantic Rainforest biome. Agroforestry Systems 80: 1-16.

Tacher, S.I.L.; Rivera, J.R.A.; Romero, M.M.M. \& Fernández, A.D. 2002. Caracterización del uso tradicional de la flora espontánea en la comunidad Lacandona de Lacanhá, Chiapas, México. Interciencia 27: 512-520.

Tamashiro, J.Y. 1989. "Estudos taxonômicos e morfológicos do gênero Piptadenia sensu Bentham no Sudeste do Brasil: avaliação das modificações taxonômicas recentemente propostas". Dissertação de Mestrado. Universidade Estadual de Campinas, São Paulo. 99p.

Toledo, V.M.; Batis, A.B.; Becerra, R.; Martínez, E. \& Ramos, C.H. 1995. La selva útil: etnobotánica cuantitativa de los grupos indígenas del trópico húmedo de México. Interciencia 20: 177-187.

Valverde, O. 1967. A fazenda de café escravocrata, no Brasil. Revista Brasileira de Geografia 29: 37-81.

Veloso, H.P.; Rangel-Filho, A.L.R. \& Lima, J.C.A. 1991. Classificação da vegetação brasileira, adaptada a um sistema universal. IBGE, Rio de Janeiro. 123p.

Vidaurre, P.J.; Paniagua, N. \& Moraes, M.R. 2006. Etnobotánica en los Andes de Bolivia. Botánica Económica de los Andes Centrales 1: 224-238. 